\title{
SCANNING ELECTRONMICROSCOPY OF THE JEJUNUM IN ENTERITIS NECROTICANS
}

\author{
P. D. Walker, T. G. C. Murrell* and L. K. NaGY \\ Wellcome Research Laboratories, Langley Court, Beckenham, Kent BR3 3 BS \\ Plates XVIII-XXIV
}

AN EPIDEMIC form of enteritis necroticans, locally known as pig-bel, occurs in children in the highlands of Papua New Guinea (Murrell and Roth, 1963; Murrell et al., 1966a). The disease is a serious public-health problem with an annual mortality of about 14 per 10000 population (Murrell et al., 1966b). It is now the commonest cause of death in Eastern Highland Hospitals among children over 1 year of age and it is estimated that approximately 750 children die from pig-bel each year. Evidence suggests that the condition is precipitated by the growth of strains of Clostridium perfringens type C (Egerton and Walker, 1964) present in small numbers in the normal intestinal flora or ingested with contaminated meat during pig feasting, with subsequent production of $\beta$ toxin leading to segmental paralysis, inflammation and necrosis of the small intestine. The normal low-protein diet, the staple sweet potato, a dietary change to meat particularly during pig feasting, and low levels of $\beta$ antitoxin in those at risk are thought to be predisposing factors in the pathogenesis of this gangrenous enteritis (Lawrence and Walker, 1976). Only small amounts of pancreatic protease, particularly trypsin which is known to destroy $\beta$ toxin, are produced by children on a low-protein diet; this, coupled with the presence of trypsin inhibitors in semi-cooked sweet potato, may be of particular importance (Lawrence, 1974, 1975).

Pig-bel may present in several ways. In the acute toxic form, with toxaemia and shock, abdominal symptoms may be prominent; in the acute surgical form there is obstruction of the small bowel and severe pain, and surgery is life-saving; and in the subacute surgical form there is a degree of small-bowel obstruction with subsequent malabsorption resulting from scarring and fibrosis. The most common form is mild and there is usually complete recovery.

How the toxin penetrates the jejunal mucosa is not clearly understood. According to Lawrence (1974), the clinical course of pig-bel reflects the amount of damage done by large amounts of toxin produced in a short period after the meat meal that invariably precedes the disease. This process is localised in time, the damage done to the gut by absorption of toxin early in the

Received 23 Nov. 1979; accepted 19 Dec. 1979.

* Present address: Department of Community Medicine, University of Adelaide, South Australia 5001. 
disease determining the clinical picture. Recovery may or may not take place from the initial necrosis and subsequent ischaemia. On the other hand, in piglet enterotoxaemias caused by the same organism there is evidence of a more progressive infection, the disease being initiated by attachment of small numbers of $C$. perfringens type $C$ to the intestinal villi with subsequent bacterial proliferation and production of toxins in close proximity to the mucosa (Arbuckle, 1972; Bergeland, 1972).

This paper describes the appearance in the scanning electron microscope of jejunal tissue from patients with pig-bel. It illustrates the role of attachment of organisms to the intestinal villi in infection and the breakdown of intestinal tissue as the disease progresses. The paper also illustrates attachment during the early stages of infection in young piglets after artificial infection with human strains of $C$. perfringens type $\mathrm{C}$.

\section{MATERIALS AND METHODS}

Human intestinal material. Resected jejunal material removed at laparotomy was preserved in $10 \%$ formol saline from four patients at differing clinical stages of pig-bel. The first specimen was resected from a 14-yr-old boy (patient no. 1) on the third day of illness with acute toxic pig-bel; the second was from a 9-yr-old boy (no. 2) who had an operation on the 5th day of symptoms; and the other two specimens were from patients (nos. 3 and 4) who were ill for 7 or more days, each with the acute surgical form of pig-bel. The four pathological specimens obtained from these patients are representative of this lethal progressive gangrenous enteritis (Murrell, 1967).

Porcine intestinal material. Four 8-12-h-old colostrum-deprived piglets were challenged orally with $10^{10}$ organisms of $C$. perfringens type C strain F2113 (Egerton and Walker, 1964). Four hours later, the piglets were killed and a portion of the infected jejunum was removed and preserved in $10 \%$ formol saline.

Scanning electronmicroscopy. Material was washed for $24 \mathrm{~h}$ in tap water, dehydrated in graded concentrations of methanol, followed by acetone. The specimen was subjected to critical-point drying and then coated with gold and mounted on a metal stub with Silver Electrodag 915 high-conductivity paint (Dag). The specimens were examined in a Philips PSEM 500 Scanning Electron Microscope (Philips, Eindhoven) at $6 \mathrm{kV}$ and an aperture of $320 \mu \mathrm{m}$.

\section{RESULTS}

\section{Human intestinal material}

The macroscopic appearance of the jejunum from patient no. 2 is shown in fig. 1. The scanning electronmicroscopic (EM) appearance of the villi of the jejunal mucosa from normal areas in all four cases was leaflike with occasional convolutions, consistent with the normal mucosal structure in children reared in similar circumstances in Uganda (Banwell, Hutt and Tunnicliffe, 1964).

At 3 days in an acute toxic case of pig-bel, necrosis of the villous tips was extensive with subepithelial gas formation giving the impression of small pinhole eruptions emerging from the epithelial surface (figs. 2, 3 and 4). Shelving necrotic epithelium was evident in areas of ulceration, and cavitation of the mucosa exposed the lamina propria and muscularis mucosae (figs. 4 and 5). Necrosis extended in a non-selective manner and involved crypt epi- 
ELECTRONMICROSCOPY OF ENTERITIS NECROTICANS

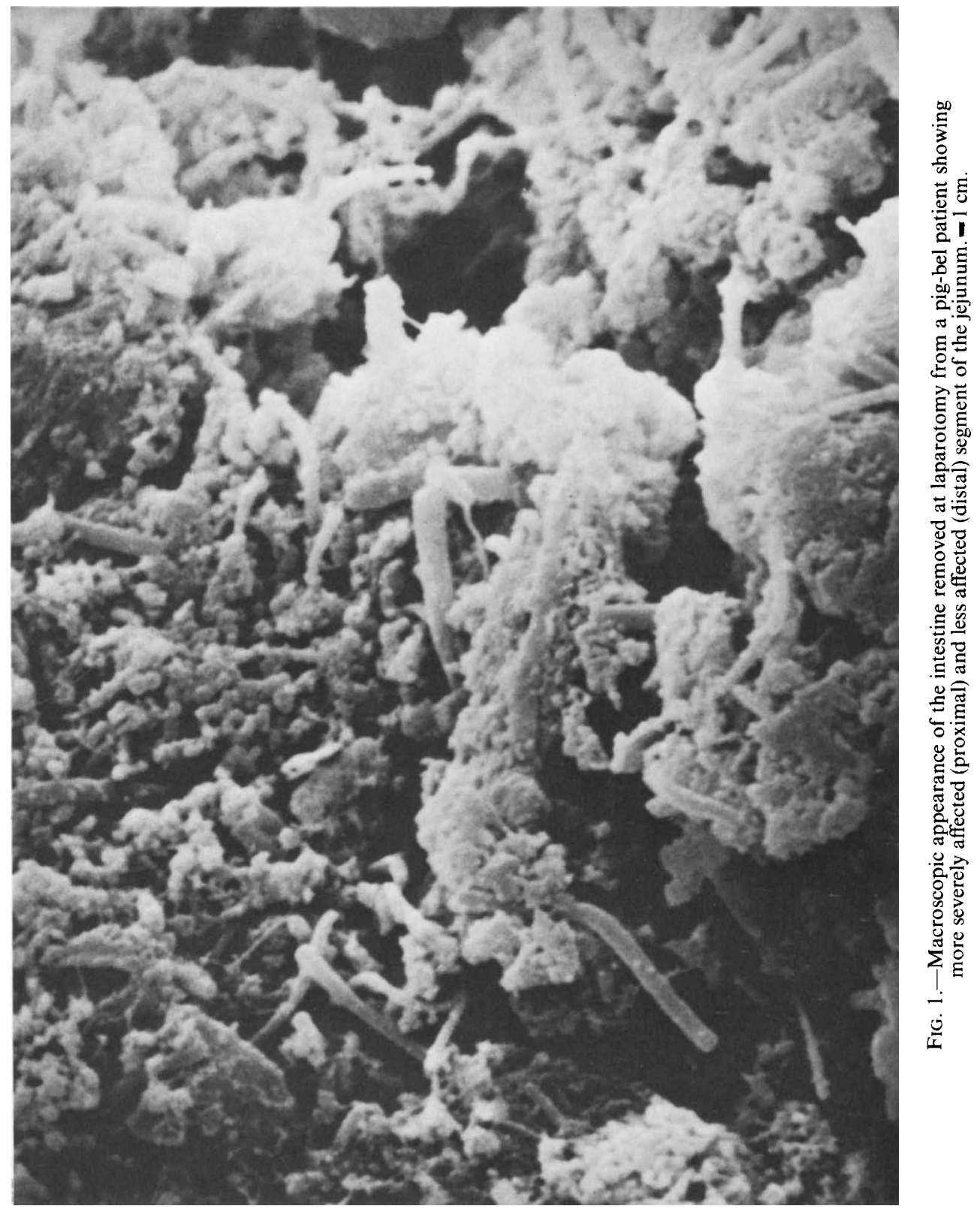




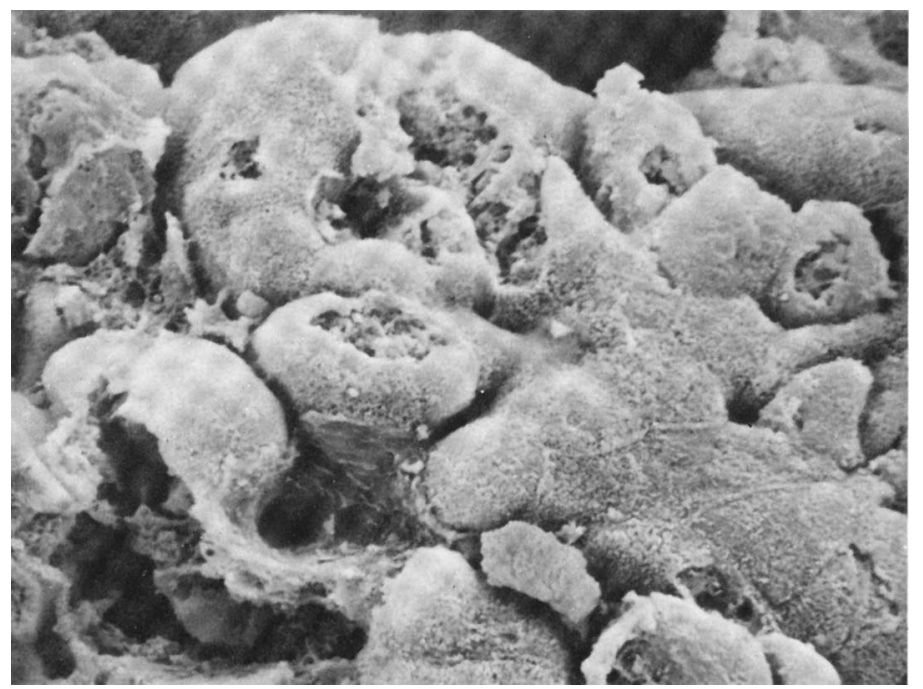

FIG. 2.-Scanning electronmicrograph of infected villi showing necrosis of the tips. $\times 1875$.

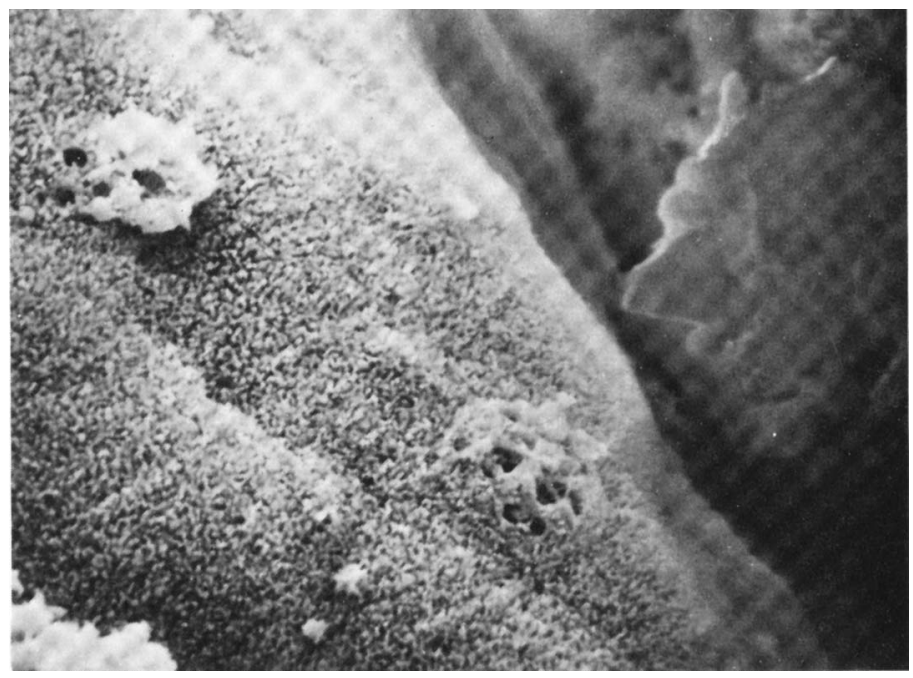

FIG. 3.-Scanning electronmicrography of infected epithelial surface showing eruptions due to subepithelial gas formation. $\times 3750$. 


\section{ELECTRONMICROSCOPY OF ENTERITIS NECROTICANS}

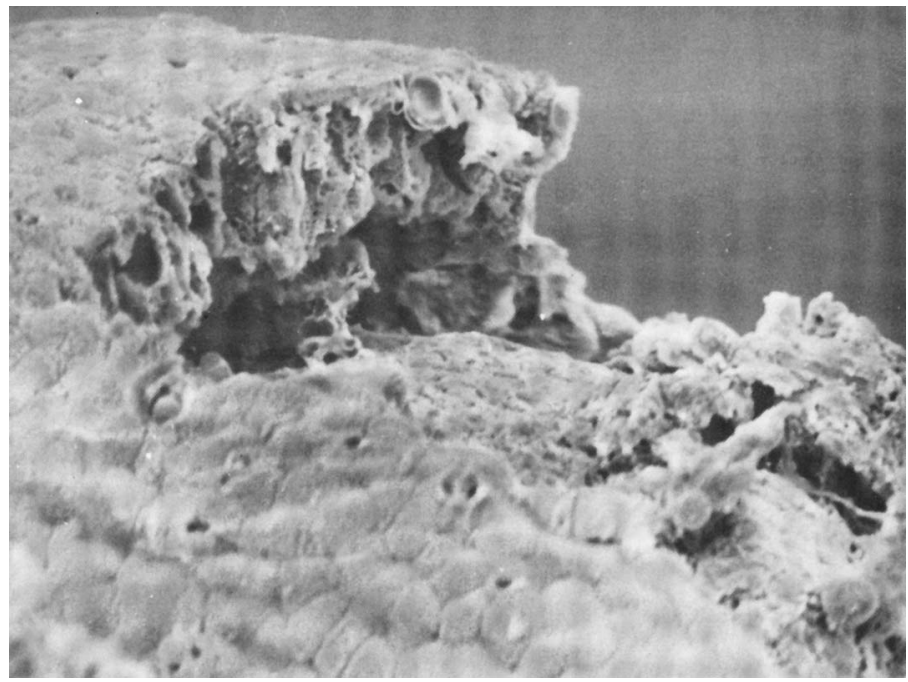

FIG. 4.-Scanning electronmicrograph of necrotic villus showing cavitation and eruptions of the epithelial surface. $\times 320$.

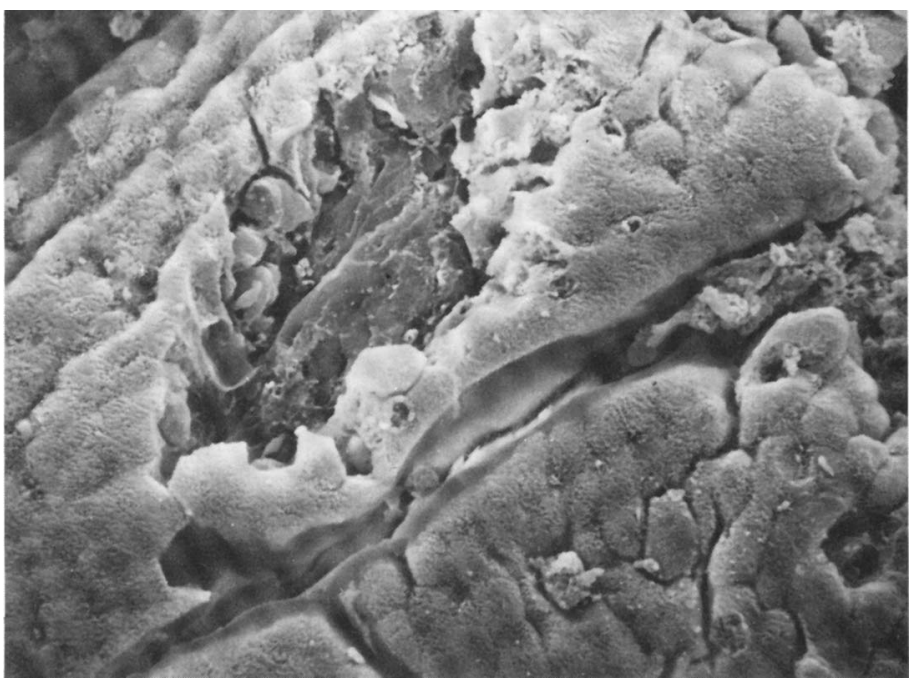

FIG. 5.-Scanning electronmicrograph of necrotic epithelium showing ulceration and cavitation of the mucosa. $\times 960$ 
thelium as well as mesenchymal elements of the lamina propria, muscularis and even lymph nodes. Filamentous organisms were associated with these cavities (figs. 6 and 8). Mucosal sloughing and peeling back of the epithelial surface then initiated the development of the pseudo-membrane which typically occurs in the jejunum at day 5-7 in acute surgical pig-bel. Surrounding these cavities and caught up in the necrotic edges of mucosal defects were numerous filamentous rods of different lengths. Most lay along the villous surface (fig. 7) and some could be seen projecting from small defects in the protective mucosa. Cocci were also present, mostly at the ulcer edges (fig. 8). Flattened plaques of tightly packed crenated cells lying across some villi represented compressed extravasated blood from micro-haemorrhages. Submucosal spreading necrosis, with haemorrhages and capillary thromboses are typical of the macroand micro-pathology of acute pig-bel. In the last case, healing was progressing in some areas of the gut while in other areas the mucosa had disintegrated and the lamina propria had started to slough off a honeycombed submucosa filled with organised gas cysts (fig. 9), the complication described as pneumatosis cystoides intestinalis (Murrell, 1966). Again the dominant organism was a filamentous rod. At the 7th day, patients are extremely toxic and the EM scanning appearances paralleled the macroscopic and light microscopic appearance of gross bowel-wall necrosis, disorganisation, subacute ulceration and extensive bacterial colonisation by mixed species of organisms. The prognosis in cases such as the last three patients is not good unless surgery is performed.

\section{Porcine intestinal material}

Four hours after infection, numerous rods could be seen adherent to the villous tips (fig. 10), and there was initial necrosis of the underlying mucosa (fig. 11).

\section{Discussion}

The scanning EM appearance of specimens from the four cases of pig-bel examined in this study representing the acute toxic and acute surgical forms of the disease dramatically showed the effect of toxins of $C$. perfringens type $C$ in progressively destroying the jejunal mucosa. Although other toxins produced by $C$. perfringens type $C$ may play a role, the importance of the $\beta$ toxin in producing these effects is supported by the recent success of $\beta$ toxoid as an immunising agent in preventing the disease (Lawrence et al., 1979). The degenerative changes seen in this study were almost identical with those described by Arbuckle (1972) in studies of the artificial infection of young piglets with $C$. perfringens type $\mathrm{C}$. With fluorescent labelled antibody and conventional histological techniques he showed that fluorescent bacillii were present around the outlines of the villi and in the lumen but that the bacilli were most densely aggregated on the villous edge rather than in the lumen. After bacterial attachment, the epithelial layer of the villus was progressively removed from the underlying lamina propria, starting in the terminal region (tip) of the villus. Subsequently, the cellular morphology of the lamina 
propria of the villi was destroyed and this necrosis was associated with the presence of large numbers of gram-positive bacilli around the remnants of the villi. Spread of the necrosis from the villi into the crypt occurred and eventually the complete necrotic mucosa could be sloughed off. Arbuckle suggested that when $C$. perfringens had become adherent it could proliferate along the villous surface and that a result of the bacterial attachment is that the toxins are brought into more intimate contact with the host.

The present study has also indicated the importance of adhesion in the infectious process. Filamentous rods consistent with the appearance of $C$. perfringens were dominant at all stages of infection on the infected tissue although many cocci were also present during the later stages. In all four cases the presence of $C$. perfringens has been identified in smears by the fluorescent staining technique (Walker, Batty and Thomson, 1971). In view of the difficulty of obtaining biopsy samples at earlier stages of the disease in man, an attempt was made to follow the initial stages of artificial infection in young piglets with a strain isolated from man. The results clearly showed the attachment of $C$. perfringens type $C$ organisms to the intestinal villi as early as $4 \mathrm{~h}$ after infection; even at that stage there was evidence of early degenerative changes at the surfaces of the villi.

These observations are consistent with the view that after attachment to the surface of a villus the organism can proliferate and give rise to the degenerative changes that we have observed with the scanning electron microscope, and that as necrosis and infection proceed the necrotic areas are colonised by other organisms.

The factors that limit initial attachment and extension of the organisms with further toxin production may vary from case to case. There is a suggestion that $\beta$ toxin may paralyse villi and prevent their normal washing effect (Parnas, 1976). This could be an important factor in initiating the disease in individuals whose inability to destroy toxins may be attributable to inadequacy of pancreatic proteases and the presence of trypsin inhibitors. Small amounts of $\beta$ toxin produced by organisms multiplying in the new conditions provided by the dietary change to a large meat meal could thus enable resident or ingested organisms to attach to the paralysed villi. Depressed exocrine pancreatic function in protein deficiency syndromes is known to favour infection with Vibrio cholerae (Gyr, Felsenfeld and Wolf, 1975) and bacterial adherence similar to what we have demonstrated in pig-bel occurs in cholera (Nelson, Clements and Finkelstein, 1976). Changes in the nature of mucus secreted and mucosal defects may also result from concurrent helminthic infestation, giardiasis or tropical sprue (Bhat et al., 1972; Tomkins et al., 1978), all of which are not uncommon in pig-bel patients in Papua. As bacterial multiplication occurs, tissue anoxia resulting from gut distension, particularly along the antimesenteric border, probably influences further anaerobic growth, attachment, gas production and toxin production. Organisms attached to shedding necrotic mucosa may be moved distally by peristaltic gut action, producing secondary seeding; this was very apparent in all specimens after 3 days.

An important factor limiting the disease in subacute and mild forms of the 
ELECTRONMICROSCOPY OF ENTERITIS NECROTICANS

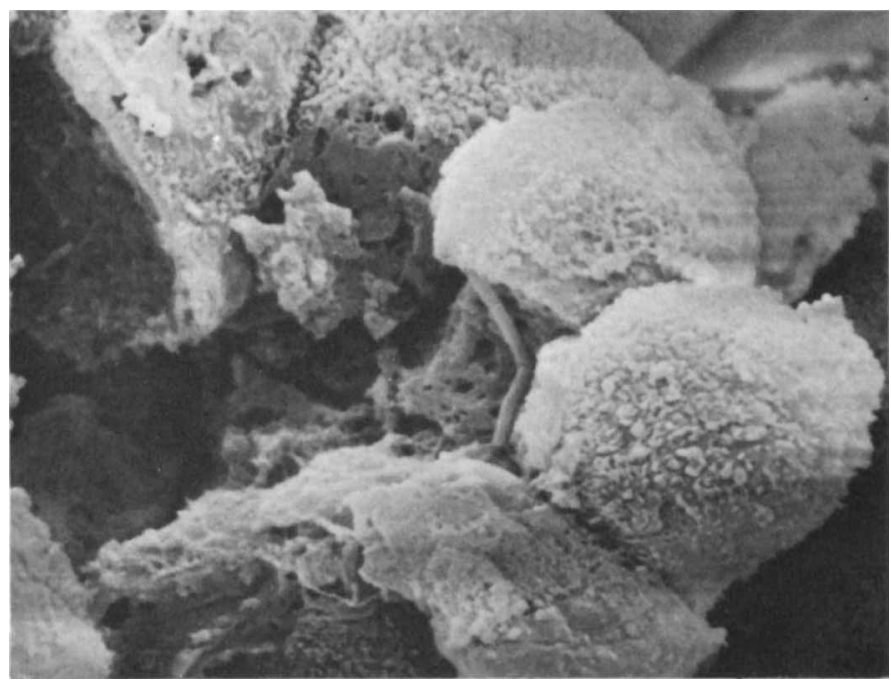

FIG. 6.-Scanning electronmicrograph showing edge of necrotic cavity with associate filamentous organisms. $\times 3750$.

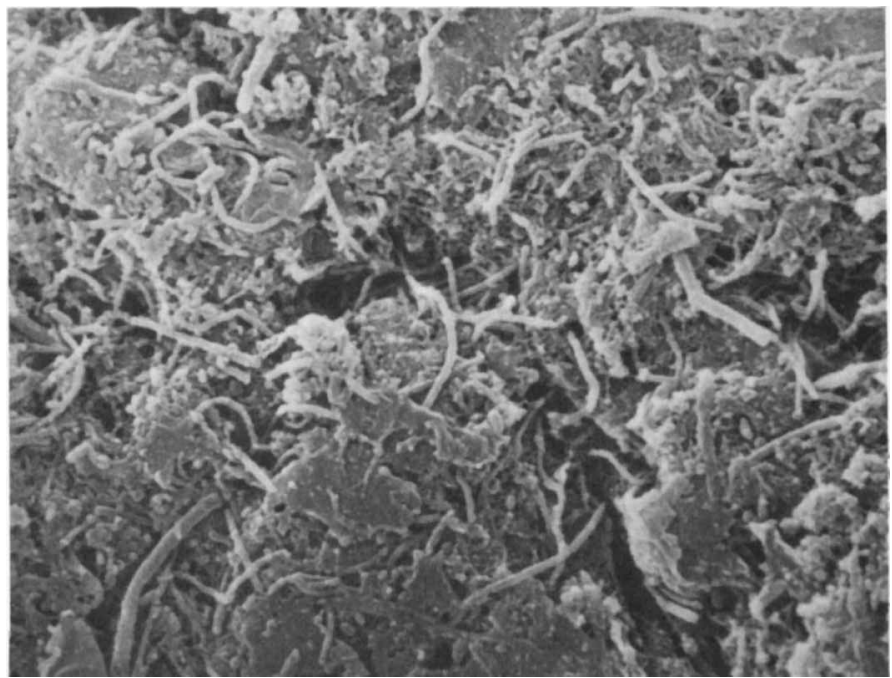

FiG. 7.- Scanning electronmicrograph of necrotic edge of the mucosa showing the presence of numerous filamentous rods lying along the villus surface. $\times 1875$. 


\section{ELECTRONMICROSCOPY OF ENTERITIS NECROTICANS}

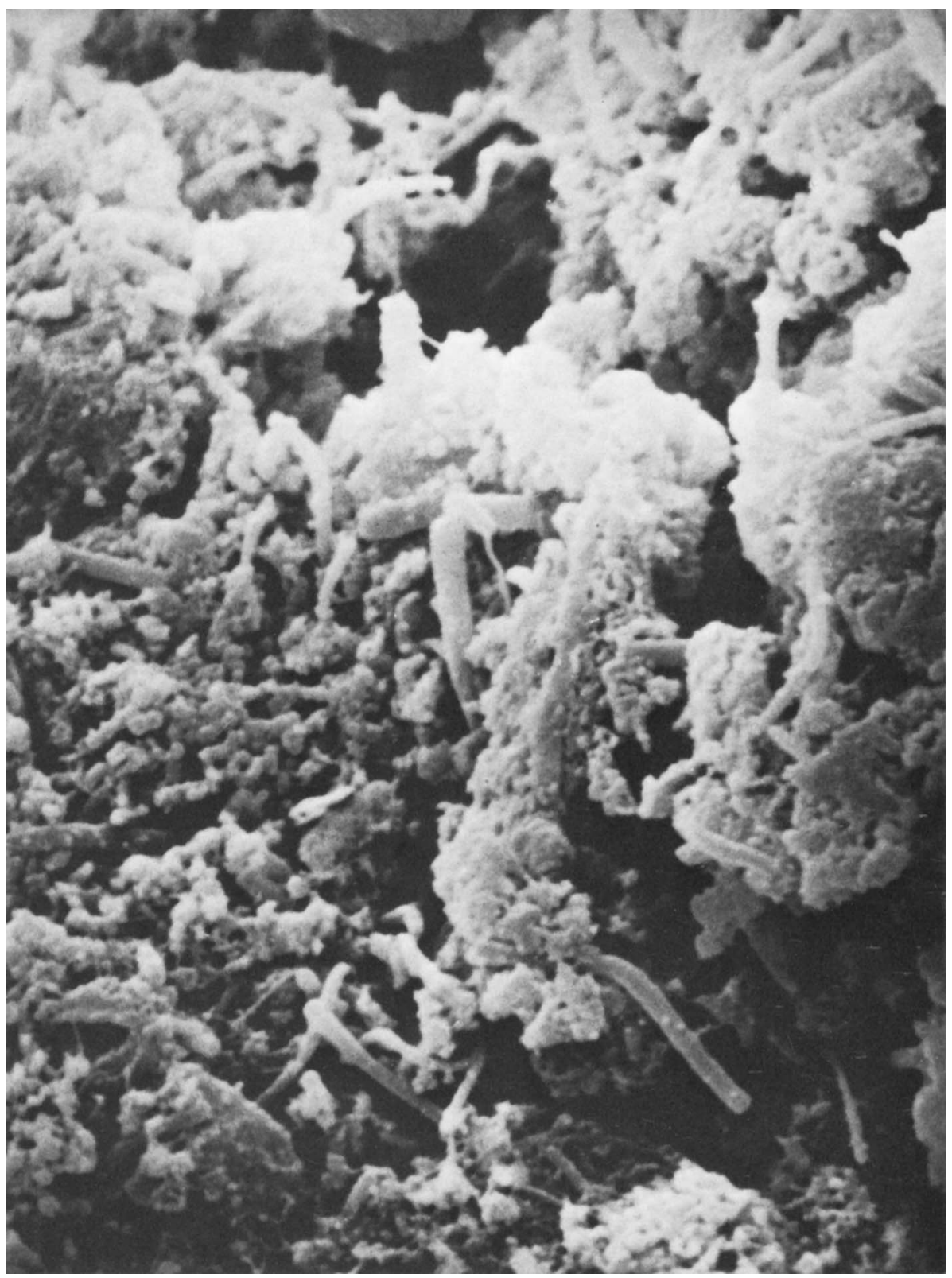

FIG. 8.--Scanning electronmicrograph of the edge of an ulcer showing filamentous organisms together with cocci. $\times 4375$. 
condition may be the neutralisation of toxin by circulating $\beta$ antitoxin preventing the necrotic changes and destruction of the mucosa. In addition, similar antibacterial mechanisms may operate here as they do in cholera (Knop and Rowley, 1975a, $b$, and $c$ ).

\section{SUMMARY}

Intestinal tissue resected at laparotomy from patients in Papua New Guinea at various clinical stages of enteritis necroticans, locally known as pig-bel, has been examined under the scanning electronmicroscope. Evidence obtained from parallel studies of experimental infection in pigs is presented. Progressive destruction of the intestinal mucosa was seen during the course of the disease in man. Numerous filamentous rods morphologically consistent with the appearance of Clostridium perfringens type $\mathrm{C}$, were seen to be attached the affected areas of gut and were associated with the necrotic tissue. The mechanism of pathogenicity includes a stage of attachment to the surfaces of jejunal villi, local multiplication, and the production of $\beta$ toxin which may be protected from tryptic digestion by the inadequacy of pancreatic protease production in susceptible subjects and by the ingestion of a trypsin inhibitor. The association of the condition with pork feasting is discussed.

We thank Dr R. A. Cook, Brisbane General Hospital, Queensland and Mr A. R. Shepherd and Mr F. S. Smith, Department of Public Health, Papua New Guinea, for case material, and Dr M. P. Alpers and Dr G. Lawrence, Papua New Guinea Institute of Medical Research, for invaluable assistance.

\section{REFERENCES}

ARBUCKLE, J. B. R. 1972. The attachment of Clostridium welchii ( $\mathrm{Cl}$. perfringens) type $\mathrm{C}$ to intestinal villi of pigs. J. Path., 106, 65.

Banwell, J. C., Hutt, M. S. AND TunNiClifFe, R. 1964. Observations on jejunal biopsy in Ugandan Africans. E. Afr. med. J., 41, 46.

Bergeland, M. E. 1972. Pathogenesis and immunity of Clostridium perfringens type $C$ enteritis in swine. J. Am. vet. med. Ass., 160, 568.

Bhat, P., Shantakumari, S., Rajan, D., Mathan, V. I., Kapadia, C. R., Swarnabai, C. and BAKER, S. J. 1972. Bacterial flora of the gastrointestinal tract in Southern Indian control subjects and patients with tropical sprue. Gastroenterology, 62, 11.

Egerton, J. R. AND WALKER, P. D. 1964. The isolation of Clostridium perfringens type C from necrotic enteritis of man in Papua New Guinea. J. Path. Bact., 88, 275.

Gyr, K., FelsENFELD, O. AND WOLF, R. H. 1975. Intestinal absorption, exocrine pancreatic function and response to Vibrio cholerae infection in protein deficient patas monkeys (Erythrocebus patas). Trans. R. Soc. trop. Med. Hyg., 69, 247.

KNOP, J. AND RowLEY, D. 1975a. Antibacterial mechanisms in the intestine. Elimination of $V$. cholerae from the gastrointestinal tract of adult mice. Aust. J.exp. Biol.med. Sci., 53, 137.

KNOP, J. AND ROWLEY, D. $1975 b$. Antibacterial mechanisms in the intestine. Elimination of $V$. cholerae from the intestines of infant mice and the role of antibody. Aust.J. exp. Biol.med. Sci., 53, 147.

KNOP, J. AND Rowley, D. 1975c. Protection against cholera. A bactericidal mechanism on the mucosal surface of the small intestine of mice. Aust. J. exp. Biol. med. Sci., 53, 155. 
LaWrence, G. 1974. Further speculation on pig-bel. Proceedings of 10th Annual Symposium Papua New Guinea Medical Society: Port Moresby, p. 207.

LaWrence, G. 1975. Recent advances in pig-bel. Proceedings 11 th Annual Symposium Papua New Guinea Medical Society: Port Moresby, p. 26.

Lawrence, G. AND Walker, P. D. 1976. Pathogenesis of enteritis necroticans in Papua New Guinea. Lancet, 1, 125.

Lawrence, G., Shann, F., Freestone, D. S. and Walker, P. D. 1979. Prevention of necrotising enteritis in Papua New Guinea by active immunisation. Lancet, 1, 227.

Murrell, T. G. C. 1966. Pig-bel-case report. Papua New Guinea med. J., 9, 68.

Murrell, T. G. C. 1967. Pig-bel-epidemic and sporadic necrotizing enteritis in the highlands of New Guinea. Australas. Ann. Med., 16, 4.

Murrell, T. G. C. AND Roth, L. 1963. Necrotizing jejunitis: a newly discovered disease in the highlands of New Guinea. Med. J. Aust., 1, 61 .

Murrell, T. G. C., Roth, L., Egerton, J., Samels, J. and Walker, P. D. 1966a. Pig-bel: enteritis necroticans. A study in diagnosis and management. Lancet, 1, 217.

Murrell, T. G. C., Egerton, J. R., Rampling, A., Samels, J. and Walker, P. D. 1966 $b$. The ecology and epidemiology of the pig-bel syndrome in man in New Guinea. J. Hyg., Camb., 64, 375 .

Nelson, E. T., Clements, J. D. and Finkelstein, R. A. 1976. Vibrio cholerae adherence and colonization in experimental cholera: electron microscopic studies. Infect. Immun., 14, 527.

Parnas, J. 1976. Über den Einfluß des Beta-Toxins von Clostridium perfringens (Typ C) auf die Motorik der Darmsegmente (in vitro). Zentbl. Bakt. ParasitKde, I. Abt. Org., 234, 243.

Tomkins, A. M., Wright, S. G., Drasar, B. S. and JaMES, W. P. T. 1978. Bacterial colonization of jejunal mucosa in giardiasis. Trans. R. Soc. trop. Med. Hyg., 72, 33.

WALKER, P. D., BATTY, I. AND ThOMSON, R. O. 1971. The localization of bacterial antigens by the use of the fluorescent and ferritin labelled antibody techniques. In Methods in microbiology, edited by J. R. Norris and D. W. Ribbons, vol. 5A. Academic Press: London \& New York, p. 219. 
ELECTRONMICROSCOPY OF ENTERITIS NECROTICANS

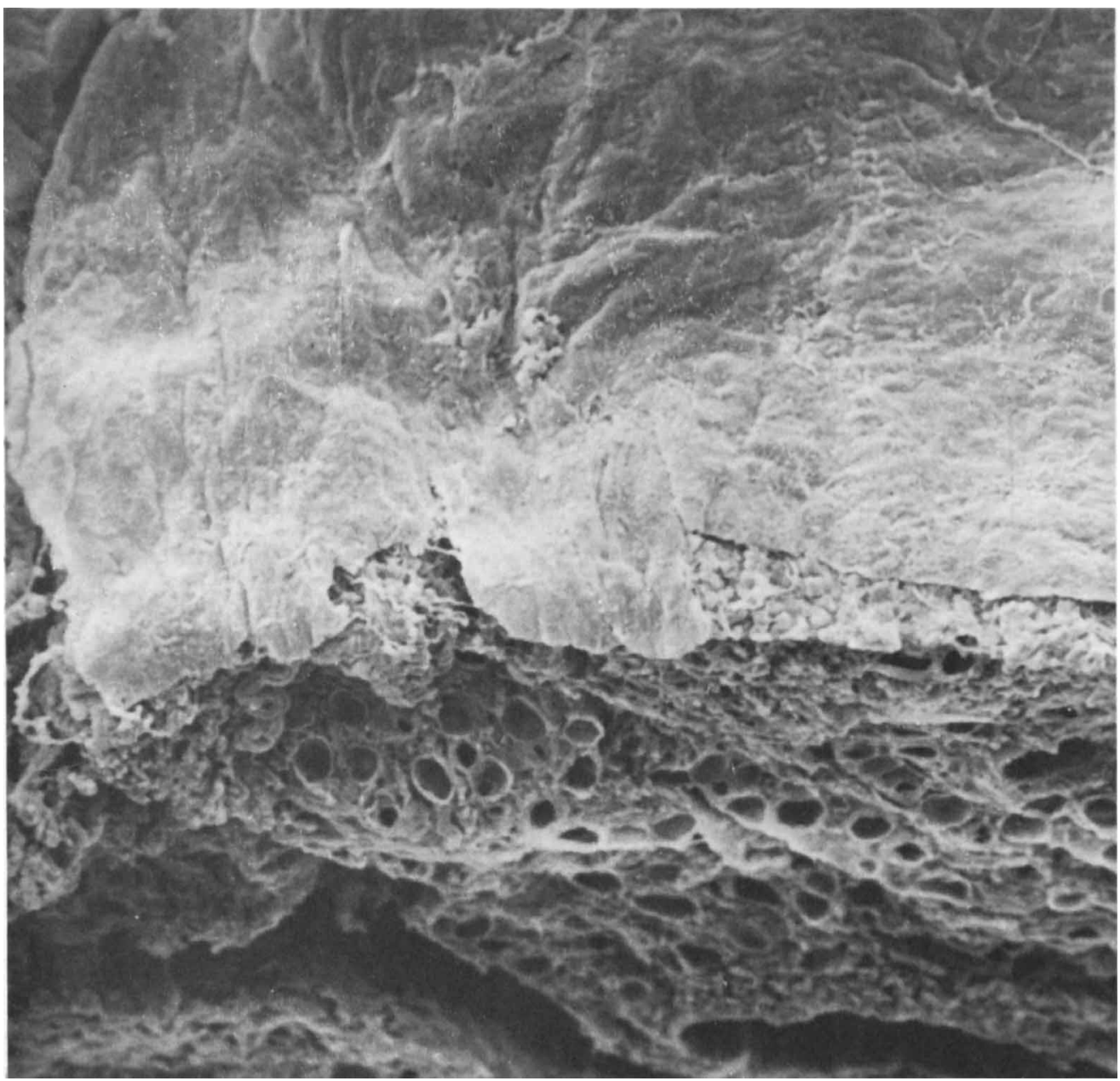

FIG. 9.-Scanning electronmicrograph of degenerating mucosa with lamina propria shedding from a honeycombed sub-mucosa filled with gas cysts. $\times 200$. 
ELECTRONMICROSCOPY OF ENTERITIS NECROTICANS

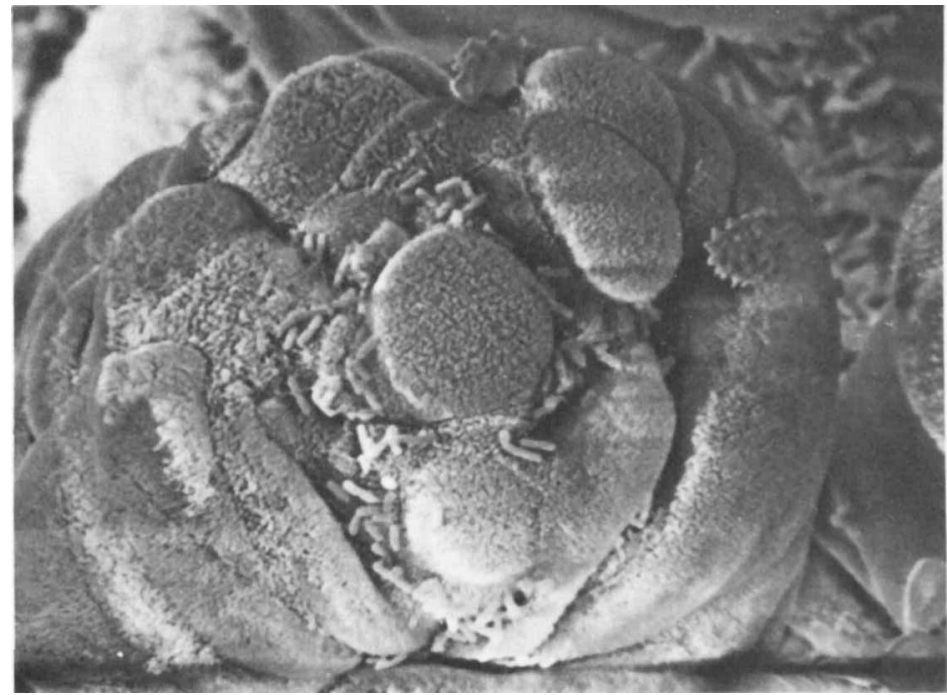

Fig. 10.-Scanning electronmicrograph of intestinal villi from a piglet $4 \mathrm{~h}$ after oral infection with $C$. perfringens type $\mathrm{C}$, showing attached organisms. $\times 2500$.

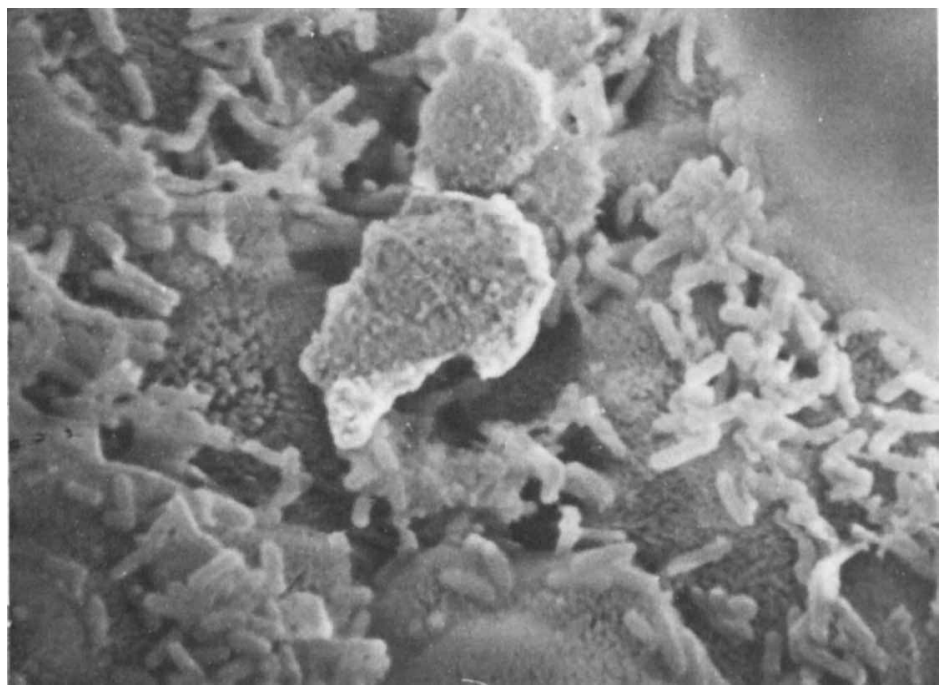

FIG. 11.-Scanning electronmicrograph of surface of porcine intestinal villus showing attached organisms and degenerating mucosal surface. $\times 5000$. 